\title{
Long-term Control of Bacteriuria with Trimethoprim-Sulphonamide
}

\author{
W. R. CATTELL, D. A. CHAMBERLAIN, I. K. FRY \\ M. A. MCSHERRY, C. BROUGHTON, F. O'GRADY
}

British Medical fournal, 1971, 1, 377-379

\begin{abstract}
Summary
Long-term antibacterial therapy with the drug combination trimethoprim-sulphonamide has been used for the treatment of 52 patients with persistent or recurrent bacteriuria. Hypersensitivity or gastrointestinal intolerance was observed in six. Bacteriuria was controlled in 36 out of 38 patients with organisms sensitive to trimethoprim-sulphonamide, 28 having received treatment for periods ranging from 6 to 49 months. Treatment was in some cases curative and in others suppressive or prophylactic. The importance of supportive measures is re-emphasized.
\end{abstract}

\section{Introduction}

The management of patients with recurrent or persistent urinary tract infection and the assessment of their response to treatment has in the past often been confused by the failure to distinguish curative, suppressive, and prophylactic usage of long-term therapy (O'Grady et al., 1969). Over the past four years we have used long-term treatment with a trimethoprim-sulphonamide combination for each of these purposes.

\section{Patients and Methods}

All patients studied were referred to a specialist nephrourological clinic. In many instances they had been extensively investigated and treated at other hospitals. They thus represent a highly selected group of subjects with intractable or recurrent infection. All patients were fully documented and investigated on their first attendance. Excretion urograms were carried out and, where appropriate, micturating cystograms were obtained. All the urograms were examined independently by two radiologists, a radiological diagnosis was made, and the degree of radiological abnormality was "scored" (Cattell et al., 1970). Dilatation of the upper urinary tract and impaired bladder emptying were separately assessed. The degree of abnormality was scorednil (0), mild (1), moderate (2), marked (3), and gross (4). Where there were both dilatation of the upper tract and defective bladder emptying the scores were summed. Blood urea was estimated in all cases, and in most of them creatinine clearance was measured. The diagnosis of urinary

St. Bartholomew's Hospital, London E.C.1

W. R. CATTELL, M.D., F.R.C.P.ED., Consultant Nephrologist

D. A. CHAMBERLAIN, M.D., M.R.C.P., Senior Medical Registrar (At present Consultant Cardiologist, Royal Sussex County Hospital, Brighton BN2 5BE)

I. K. FRY, D.M., F.F.R., Consultant Radiologist

M. A. MCSHERRY, S.R.N., Nurse/Research Assistant

F. O'GRADY, M.D., M.R.C.PATH., Professor of Bacteriology

Regional Renal Unit, St. Leonard's Hospital, London N.1

C. BROUGHTON, S.R.N., Nurse/Research Assistant infection was based on finding $10^{5}$ or more organisms per $\mathrm{ml}$ in two or three successive midstream samples of urine as previously described (O'Grady et al., 1969).

The protocol used for the management of these patients is represented schematically in the Diagram. The standard

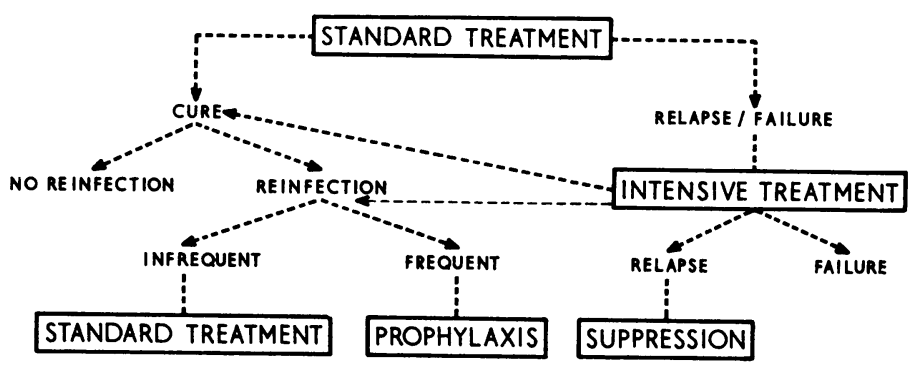

Schema of treatment regimen.

treatment during this study was ampicillin $(500 \mathrm{mg}$ sixhourly) for two weeks, unless the organism was resistant in vitro when tetracycline ( $250 \mathrm{mg}$ six-hourly) or nitrofurantoin ( $100 \mathrm{mg}$ six-hourly) for two weeks was given, in that order of preference. Some patients harboured multiresistant or mixed organisms and were treated with appropriate agents, singly or in combination according to in vitro sensitivity results. For example, patients infected with pseudomonas were treated with polymyxin, gentamicin, or carbenicillin.

The urine was re-examined 48 hours after the beginning and 48 hours after the cessation of drug administration to assess the response to treatment. The success of treatment was gauged by examination of the urine one to two weeks and again six weeks after cessation of therapy. Patients who responded were seen again at 3,6 , and 12 months, and then were discharged with instructions to reattend if a further attack developed. Patients who relapsed (that is to say, the same organism still sensitive to the original agent reappeared) were re-treated with the same agent in high dosage or with the same dosage for a further four weeks. Those who responded were followed as before. Those who responded but were known previously to have become repeatedly infected and those who required intensive therapy were started on long-term treatment with trimethoprim-sulphonamide in the last 48 hours of initial treatment. In some instances the infecting organism was resistant to trimethoprimsulphonamide. Nevertheless, such patients were treated with this combination in the hope that if infection was eradicated by initial treatment it would act as a prophylactic, and if infection was not eradicated it would act, to some extent at least, as a suppressive.

Initially the drugs were given as separate tablets: trimethoprim in a dose of $100 \mathrm{mg}$ six-hourly combined with sulphadimidine $500 \mathrm{mg}$ six-hourly. Later, sulphafurazole in the same dosage was more commonly used, and most recently sulphamethoxazole in the form of the brand drug Septrin was used. If the urine remained sterile the frequency of administration of trimethoprim-sulphonamide was progressively reduced 
from six-hourly to 12-hourly, nightly, alternate nightly, and finally nightly twice a week.

Patients receiving long-term treatment were taught to inoculate plates with their urine by the filter strip method (Leigh and Williams, 1964), the plates being sent to the laboratory for examination. In addition, the patients were seen at monthly and later less frequent intervals.

\section{Results}

Between August 1965 and December 196952 patients had been introduced to long-term prophylactic or suppressive therapy, treatment by other means having failed. In six patients treatment had to be discontinued because of intolerance to the drug combination (rash or other evidence of hypersensitivity in five patients and persistent nausea, vomiting, and gastrointestinal upset in one patient). Treatment with the trimethoprim-sulphonamide combination failed to control the bacteriuria in 10 patients. In 8 of the 10 at least one of the initial infecting organisms was resistant to the drug combination, pseudomonas being present in six patients. Four of the patients infected with organisms resistant to trimethoprim-sulphonamide were apparently controlled by initial intensive therapy with other antibiotics, but all subsequently suffered "break-through" infections with reappearance of the bacterial species responsible for the original infection.

There remained 36 patients, all of whom had their bacteriuria controlled at the time of assessment, and 28 of them had then received the drug combination for periods ranging from 6 to 49 months (Table I). In 11 of these patients

TABLE I-Infection controlled on Diminishing Dosage of Trimethoprimsulphonamide for more than 6 Months

\begin{tabular}{|c|c|c|c|c|c|}
\hline \multicolumn{2}{|l|}{ Current Dosage } & $\begin{array}{c}\text { No. } \\
\text { of } \\
\text { Patients }\end{array}$ & $\begin{array}{c}\text { No. with } \\
\text { Blood Urea } \\
>45 \mathrm{mg} / 100 \mathrm{ml}\end{array}$ & $\begin{array}{c}\text { Radiological } \\
\text { Score } \\
\text { (see text) }\end{array}$ & $\begin{array}{l}\text { Total Duration } \\
\text { of Therapy } \\
\text { in Months }\end{array}$ \\
\hline $\begin{array}{l}\text { Twice daily } \quad . \\
\text { Nightly } \\
\text { Alternate nights }\end{array}$ & $\begin{array}{l}\ldots \\
\because\end{array}$ & $\begin{array}{l}3 \\
3 \\
9\end{array}$ & $\begin{array}{l}1 \\
1 \\
2\end{array}$ & $\begin{array}{l}6,5,2 \\
3,0,5 \\
1,1,2,1,5\end{array}$ & $\begin{array}{l}7,8,10 \\
12,14,18 \\
7,7,8,9,10\end{array}$ \\
\hline $\begin{array}{l}\text { Twice weekly .. } \\
\text { Once weekly }\end{array}$ & . & 12 & 3 & $\begin{array}{l}4,5,2,2 \\
0,3,1,3 \\
3,1,1,3 \\
1,0,1,0 \\
4\end{array}$ & $\begin{array}{l}10,22,27,44 \\
8,8,8,6 \\
12,14,19,24 \\
24,26,35,49 \\
9\end{array}$ \\
\hline
\end{tabular}

treatment was continuing on diminishing dosage and in 17 it had been stopped (Tables II and III). In some, the drug was evidently operating suppressively rather than curatively, since the same sensitive organism reappeared in the urine of two patients when the dosage was reduced below a certain level and in 10 of the 17 patients in whom treatment was stopped. In one of these 10 treatment had been continued for two periods of 21 and 6 months respectively, only for bacteriuria to recur on cessation of treatment on both occasions (Table I). All of these patients were readily recontrolled by increasing the dose or reinstituting treatment. In the patients whose treatment was stopped, organisms reappeared within two weeks in four, in one to two months in five, and in four months in two (Table II). In the remaining seven patients in

TABLE II-Patients in whom Treatment was stopped and Infection recurred

\begin{tabular}{|c|c|c|c|c|c|}
\hline$\underset{\text { Dosage }}{\text { Minimum }}$ & $\begin{array}{c}\text { No. } \\
\text { of } \\
\text { Patients }\end{array}$ & $\begin{array}{l}\text { Duration of } \\
\text { Treatment in } \\
\text { Months }\end{array}$ & $\begin{array}{l}\text { Time to } \\
\text { Recurrence } \\
\text { in Weeks }\end{array}$ & $\begin{array}{l}\text { Radiological } \\
\text { Score }\end{array}$ & $\begin{array}{l}\text { Blood Urea } \\
\mathrm{mg} / 100 \mathrm{ml}\end{array}$ \\
\hline $\begin{array}{ll}\text { 2/day } & \ldots \\
\text { 1/day } & \ldots \\
\text { 1/2 days } & \ldots \\
\text { 2/week } & . \\
\text { 1/week } & .\end{array}$ & $\begin{array}{l}2 \\
2 \\
1 \\
4 \\
2\end{array}$ & $\begin{array}{l}6^{*}, 10 \\
8^{*}, 12 \\
16 \\
7,9,12,21 \dagger \\
6 \dagger, 8\end{array}$ & $\begin{array}{l}1,16 \\
1,2 \\
6 \\
4,4,8,1 \\
2,16\end{array}$ & $\begin{array}{l}5,2 \\
3 \\
4 \\
1,3,3,0 \\
0,0\end{array}$ & $\begin{array}{l}28,21 \\
51,32 \\
28 \\
20,46,24,60 \\
60,25\end{array}$ \\
\hline
\end{tabular}

*Infected with Proteus mirabilis. Remainder infected Escherichia coli. tSame patient: two periods of treatment. whom treatment was stopped no recurrence has been observed during follow-up of between 1 and 24 months (Table III).

TABLE III-Patients in whom Treatment was stopped without Recurrence of infection

\begin{tabular}{|c|c|c|c|c|c|}
\hline$\underset{\text { Dosage }}{\text { Minimum }}$ & $\begin{array}{c}\text { No. } \\
\text { of } \\
\text { Patients }\end{array}$ & $\begin{array}{l}\text { Duration of } \\
\text { Treatment } \\
\text { in Months }\end{array}$ & $\begin{array}{l}\text { Time of } \\
\text { Follow-up } \\
\text { in Months }\end{array}$ & $\begin{array}{l}\text { Radiological } \\
\text { Score }\end{array}$ & $\begin{array}{l}\text { Blood Urea } \\
\mathrm{mg} / 100 \mathrm{ml}\end{array}$ \\
\hline $\begin{array}{ll}1 / 2 \text { days } & . \\
2 / \text { week } & \cdots \\
1 / \text { week } & \ldots\end{array}$ & $\begin{array}{l}2 \\
4 \\
1\end{array}$ & $\begin{array}{l}9,44^{*} \\
3,10,10,24 \\
9 t\end{array}$ & $\begin{array}{l}3,1 \\
12,18,24,2 \\
1\end{array}$ & $\begin{array}{l}1,2 \\
3,0,0,1\end{array}$ & $\begin{array}{l}32,39 \\
20,30,39,44 \\
30\end{array}$ \\
\hline
\end{tabular}

All patients infected with Escherichia coli except * (Proteus mirabilis) and + (Proteus mirabilis and Escherichia coli).

Comparison of patients with or without recurrence shows no significant difference with respect to the causal organism, duration of treatment, minimum dose at the time of cessation of treatment, radiological abnormality, or renal function (Tables II-IV).

TABLE IV-Relation of Response to Treatment and Radiological Findings

\begin{tabular}{l|c|c|c|c|c} 
& & \multicolumn{3}{|c|}{ Radiological Score (see Text) in } \\
Patients Who were:
\end{tabular}

\section{Discussion}

The prevention of recurrence of urinary tract infection by chemotherapy has until recently remained a largely unobtained objective. The need for such control has been called in question, doubt having arisen whether recurrent infection in adults with otherwise normal urinary tracts leads to significant progressive renal damage (Hodson, 1969). While clear-cut evidence for or against this danger must await further study there can be few who would not accept the need to prevent the recurrent distress commonly associated with symptomatic bacteriuria, notwithstanding the cost and potential hazard of frequent or long-continued antibacterial therapy.

The present study of long-term antibacterial therapy with the drug combination trimethoprim-sulphonamide was confined to patients with persistent or recurrent bacteriuria. For this reason the number studied is necessarily small. In all the patients reported numerous previous courses of antibacterial therapy, often extending over many years, had already failed. In an attempt to effect long-term control, trimethoprimsulphonamide therapy was started in the last 48 hours of an initial (if necessary intensive) course of treatment and was subsequently continued. Thus the drug combination was not used for initial treatment in these patients but was used as supportive therapy following treatment with other agents to which the infecting organism was sensitive in vitro. With this management four principal results may be expected.

(1) Initial (if necessary intensive) therapy may fail to eradicate the infection. There were six such patients. Four were infected 
with organisms resistant to trimethoprim-sulphonamide and not surprisingly long-term administration of the combination was a total failure. The other two were infected with organisms sensitive to trimethoprim-sulphonamide and these organisms persisted despite treatment. One of these patients had severe analgesic nephropathy and recurrent acute uraemia due to obstructive uropathy. The second had calculus disease with severe chronic renal failure (glomerular filtration rate $6 \mathrm{ml} / \mathrm{min}$ ). On theoretical grounds the failure of treatment in both cases might be expected to result from inability to achieve a significant concentration of both drugs in the urine. Sharpstone (1969), however, claims that high urine concentrations may still be obtained in the presence of advanced renal disease.

(2) Initial treatment with appropriate agents may apparently eradicate from the urine an organism (or organisms) sensitive to these agents but resistant to trimethoprim-sulphonamide. If the organisms are not in fact eradicated but simply markedly suppressed by the initial treatment they will in due course emerge through the trimethoprim-sulphonamide treatment to give rise to "break-through" infections. Such break-through infections occurred in four patients. These infections may be controlled by re-treating with the initial or another agent superimposed on the continuing trimethoprim-sulphonamide therapy. We originally thought that there was benefit to be derived in this way (O'Grady et al., 1969) but continuing experience in the four patients mentioned makes us doubtful whether long-term trimethoprim-sulphonamide made a significant contribution to their management.

(3) Initial treatment with immediate institution of long-term trimethoprim-sulphonamide may eradicate an organism sensitive to both. If when treatment is stopped the organism promptly reappears the long-term treatment has simply prolonged the suppressive effect of the agent used for the initial treatment. In 11 patients who had their drug stopped the organism reappeared in the urine within a week in three, within two weeks in two, and within a month in two. In the remaining four patients infection reappeared after six weeks, two months, and four months (two patients). It is difficult to believe that these latter cases represent relapse of the initial infection after such a time interval, and it is more likely that they represent reinfection, the drug treatment having played a prophylactic part until its withdrawal. In all patients control was re-established when treatment with trimethoprim-sulphonamide was resumed.

(4) Treatment may be curative. In seven patients treatment was stopped and the organism did not reappear. Since treatment was consecutive there is no way of being certain that long-continued trimethoprim-sulphonamide was responsible for this curative effect, but since the patients had failed assorted previous courses of antibacterial therapy it seems very likely that it was so.

A remarkable feature of the present study has been the very low dosage of drug combination required to control the bacteriuria. It was originally questioned whether such small doses could have any suppressive or prophylactic effect. Their effectiveness is, however, evidenced by the fact that two patients had recurrence of bacteriuria on reduction of the dose from thrice weekly to twice weekly and were recontrolled on a minimum of thrice-weekly and nightly doses. Similarly, the high relapse rate following the cessation of low-dose treatment (Table II) must be accepted as proof of antibacterial effectiveness.

Whether the favourable results obtained in the present series are related entirely to the use of trimethoprimsulphonamide or are conditioned in part by the manner in which the drugs were used is impossible to tell. Nor do we know whether similar results would be obtained by using other antibacterial agents in the same way, but the success of the trimethoprim-sulphonamide combination must be attributed in part to the antibacterial effectiveness of very low concentrations of these drugs combined with their prolonged half-life in the body (Cattell et al., 1968; Schwartz and Ziegler, 1969).

It is undoubtedly true that the success of any form of drug treatment must relate to the manner in which the drug is used. Recurrent bacteriuria represents a failure of normal defence mechanisms allowing the establishment and multiplication of bacteria within the urinary tract. Treatment is likely to be facilitated if intrinsic bacterial clearance mechanisms can be enhanced. There is a unique opportunity in the urinary tract to manipulate the defence mechanisms by the use of a high fluid intake and frequent complete bladder emptying. Antibacterial agents can then be used to the best advantage to reduce and arrest bacterial growth, allowing host mechanisms to eliminate the organism (Cattell et al., 1968). Thus patients on long-term treatment were encouraged to increase their fluid intake to at least 3 litres per day and to practise regular, frequent, and complete (if necessary double or triple) micturition. In addition, because of the importance of the overnight period with respect to bacterial multiplication (O'Grady and Cattell, 1966; Cattell et al., 1968) all patients were advised to take one dose of drugs last thing at night after bladder emptying. This was believed to be especially important where daily or less frequent treatment was given.

Possibly because of the low dosage employed, long-term treatment with trimethoprim-sulphonamide was distinguished by the infrequency of side effects in the form of gastrointestinal disturbance. The possibility that this drug combination might lead to folic acid deficiency anaemia or other haematological disturbance was investigated and is the subject of a separate study (A. H. Waters et al., in preparation). No evidence of any such disturbance was found in these patients despite the prolonged period of treatment.

We are indebted to the Board of Governors and the Joint Research Board, St. Bartholomew's Hospital, and to the North-east Metropolitan Regional Hospital Board for grants towards the cost of this work and to Burroughs Wellcome Ltd. for generous supplies of trimethoprim.

\section{References}

Cattell, W. R., Sardeson, J. M., Sutcliffe, M. B., and O'Grady, F. (1968) In Urinary Tract Infection, ed. F. O'Grady and W. Brumfitt, p. 212. In Urinary Tract Infection, ed. F.

Cattell, W. R., et al. (1970). British fournal of Urology, 42, 290.

Cattell, W. R., et al. (1970). British Fournal of Urology, 42,
Hodson, C. J. (1969). Fournal of Infectious Diseases, 120, 54.

Leigh, D. A., and Williams, J. D. (1964). Fournal of Clinical Pathology, 17, 498

O'Grady, F., and Cattell, W. R. (1966). British fournal of Urology, 38, 149.

O'Grady, F., et al. (1969). Postgraduate Medical fournal, 45, November Suppl., p. 61 .

Schwartz, D. E., and Ziegler, W. H. (1969). Postgraduate Medical Fournal, 45, November Suppl., p. 32.

Sharpstone, P. (1969). Postgraduate Medical fournal, 45, November Suppl., p. 38 . 